\title{
CONTÁTIL: (RE)ADAPTAÇÃO DO MATERIAL DOURADO PARA DEFICIENTES VISUAIS
}

\author{
Maria Adelina Raupp Sganzerla, PPGECIM, ULBRA, masganzerla@gmail.com \\ Marlise Geller, PPGECIM, ULBRA, marlise.geller@gmail.com
}

\begin{abstract}
Resumo: Este artigo é um recorte da pesquisa de Mestrado que desenvolveu uma Tecnologia Assistiva, a Contátil, a qual consiste em uma (re)adaptação do Material Dourado à realidade das crianças deficientes visuais, tendo como base o design instrucional, a acessibilidade e a usabilidade. A Contátil é constituída de cubos, barras e placas. Para a movimentação dos blocos, foram utilizados motores de passos, controlados por sistema embarcado. Para sua validação realizou-se uma pesquisa do tipo qualitativa, através de entrevista semiestruturada, com 19 professores licenciados em Matemática ou professores que atuam em Sala de Recursos, todos com experiência em ensino de Matemática para cegos.
\end{abstract}

Palavras-chave: tecnologia assistiva, design instrucional, usabilidade, material dourado, deficiência visual.

\section{CONTÁTIL: A (RE)ADAPTATION OF THE GOLDEN BEAD MATERIAL FOR THE VISUALLY IMPAIRED}

Abstract: This article is part of a MSc dissertation that developed Contátil, an Assistive Technology that included the (re)adaptation of the Golden Bead Material to the reality of visually impaired children, based on instructional design, accessibility, and usability. Contátil comprises cubes, bars, and plates. Step-engines controlled by an embedded system were used to move blocks. The validation of the technology was based on a qualitative research, using a semistructured interview with 19 Mathematics teachers that specialized in the use of special resources, all of whom were experienced in the teaching of Mathematics to the visually impaired.

Keywords: assistive technology, instructional design, usability, golden bead material, visual impairment.

\section{INTRODUÇÃO}

A cegueira é uma das deficiências encontradas na realidade escolar, o que faz com que a adaptação do material seja necessária, pois uma criança cega deve ser estimulada a partir dos seus outros sentidos, tato, audição, olfato, visto que a falta de visão não permite o uso de certos recursos visuais. As Tecnologias Assistivas são grandes aliadas da educação nesse sentido, pois trazem a possibilidade de adaptação.

Este trabalho é um recorte de uma pesquisa de Mestrado, do Programa de PósGraduação em Ensino de Ciências e Matemática (PPGECIM) da ULBRA Canoas/Brasil, integrante do Programa Observatório da Educação/2010-2014 (OBEDUC-CAPES/2010), que buscou investigar quais as potencialidades da Contátil, uma Tecnologia Assistiva desenvolvida para o ensino de conceitos básicos de Matemática considerando a deficiência visual.

A ideia da Contátil surgiu a partir de pesquisas e estudos realizados no LEI (Laboratório de Estudos de Inclusão), integrante do Projeto "Estratégias de ensino e de aprendizagem com alunos de inclusão na educação básica: intervenções pedagógicas na área de matemática”, aprovado no Edital UNIVERSAL-MCTI/CNPq N 14/2013, onde se percebeu que o Material Dourado poderia ser (re)adaptado à realidade das crianças 
deficientes visuais. Dessa forma, a Contátil é constituída de cubos, barras e placas. Seu nome originou-se da junção das palavras contar e tátil.

Sua validação foi efetivada através da interação e entrevista com 19 professores, licenciados em Matemática e/ou que atendem em sala de recursos, todos com experiência em Ensino de Matemática com alunos cegos e/ou baixa visão.

\section{TECNOLOGIA ASSISTIVA NA VISÃO DO DESIGN INTRUCIONAL}

Entende-se por Tecnologias Assistivas (TA), todo equipamento ou programa de computador capaz de auxiliar de alguma forma as pessoas com deficiência, sejam elas deficientes físicas ou mentais, idosas e ainda aquelas com mobilidade reduzida por algum fator externo, como, por exemplo, uma perna ou braço engessado.

Santarosa (2002, p. 66) refere-se a TA como um, conjunto de recursos que, de alguma maneira, contribui para proporcionar às PNE (Pessoas com Necessidades Especiais) maior independência, qualidade de vida e inclusão social, por meio de um suplemento (prótese), da manutenção ou devolução de suas capacidades funcionais. Esses recursos vão desde uma simples bengala, um par de óculos, cadeiras de rodas, até complexos sistemas computadorizados que permitem o controle do ambiente e até a própria expressão do indivíduo.

Bersch (2008, p. 2) define TA, como sendo "um arsenal de recursos e serviços que contribuem para proporcionar ou ampliar habilidades funcionais de pessoas com deficiência e consequentemente promover vida independente e inclusão”.

O objetivo maior da TA, para Bersch (2013, p. 2), é "proporcionar à pessoa com deficiência maior independência, qualidade de vida e inclusão social, através da ampliação de sua comunicação, mobilidade, controle de seu ambiente, habilidades de seu aprendizado e trabalho".

Portanto, a TA está relacionada ao cotidiano das pessoas com deficiência, possibilitando uma autonomia em suas tarefas diárias, escolares e profissionais e principalmente contribuindo para uma inclusão social.

Quando desenvolvemos alguma tecnologia, faz-se necessário ajustar as especificações do desenho universal, do design instrucional, da usabilidade e da acessibilidade, de tal forma que essa possa abranger uma gama maior de usuários, sejam eles pessoas com ou sem deficiência.

O Decreto $\mathrm{N}^{\circ}$ 5.296, de 02 de dezembro de 2004, dispõe em seu Art. $8^{\circ}$, para fins de acessibilidade, inciso IX, considerando o Desenho Universal:

concepção de espaços, artefatos e produtos que visam atender simultaneamente a todas as pessoas, com diferentes características antropométricas e sensoriais, de forma autônoma, segura e confortável, constituindo-se nos elementos ou soluções que compõem a acessibilidade (BRASIL, 2004).

Carvalho (2003, p. 79) apresenta o conceito de desenho universal como sendo "produtos e construções acessíveis e utilizáveis por todos os indivíduos, independentemente de possuírem ou não deficiências”.

De acordo com o Instituto Nacional para a Reabilitação (INR, 2014), o Desenho Universal está estruturado com base em sete princípios:

1. Utilização equitativa: o design é útil e comercializável por qualquer grupo de pessoas com habilidades diferenciadas.

2. Flexibilidade de utilização: atende a uma gama diferenciada de preferências e capacidades individuais. 
3. Utilização simples e intuitiva: de fácil compreensão, independentemente da experiência do usuário, de seus conhecimentos, aptidões linguísticas ou níveis de concentração.

4. Informação perceptível: fornece ao usuário a informação necessária, independentemente de sua capacidade intelectual ou motora.

5. Tolerância ao erro: minimiza riscos e consequências negativas decorrentes de ações acidentais ou involuntárias.

6. Mínimo esforço físico: pode ser utilizado de forma eficaz e confortável com um mínimo de fadiga.

7. Dimensão e espaço de abordagem e de utilização: dimensão adequada para a abordagem, manuseio e utilização, independentemente da estatura, mobilidade ou postura do utilizador.

O Desenho Universal é considerado uma forma de concretização da acessibilidade, usabilidade e promoção da inclusão social.

Galvão Filho (2009, p. 144) afirma que o conceito de desenho universal é importante para a criação de Tecnologias Assistivas, pois “devem ser concebidas, projetadas, com vistas à participação, utilização e acesso de todas as pessoas”. O autor ainda fala que ao projetar algo, este deve poder ser utilizado por diversas pessoas, com ou sem limitações; sendo assim, deve possuir recursos capazes de satisfazer a diversos sentidos,

portanto, com a aplicação do conceito de Desenho Universal se faz a transição de uma realidade de segregação, de tutela, de paternalismo, para uma realidade de cidadania, de equiparação de oportunidades e de sociedade inclusiva (GALVÃO FILHO, 2009, p. 144).

Nesse artigo iremos utilizar o conceito de design instrucional apresentado por Filatro (2008) que diz respeito às atividades ligadas à educação. Para entendimento do termo, é necessário definir as palavras design e instrução.

Como design consideramos "o resultado de um processo de atividade (produto), em termos de forma e funcionalidade, com propósitos e intensões claramente definidos" enquanto instrução é "a atividade de ensino que se utiliza da comunicação para facilitar a aprendizagem” (FILATRO, 2008, p. 3). Quando falamos, portanto, em desenvolvimento de produto, de uma TA, a usabilidade e a acessibilidade devem integrar o projeto do design instrucional.

A NBR ISO/IEC 9126-1 (1991, p. 9), apresenta o conceito de usabilidade como sendo a "capacidade do produto de software de ser compreendido, aprendido, operado e atraente ao usuário, quando usado sob condições especificadas".

O conceito apresentado pela NBR ISO/IEC 9126-1 é bastante abrangente e se aplica tanto aos sistemas que possuem uma interface gráfica para o usuário, como também para o hardware, quando este pode ser manipulado, como é o caso da Contátil.

Por interface os autores Barbosa e Silva (2010, p. 25) entendem como sendo "um sistema interativo que compreende toda a porção do sistema com a qual o usuário mantém contato físico (motor ou perceptivo) ou conceitual durante a interação". O contato físico com a interface ocorre através dos dispositivos mecânicos ou eletrônicos, o hardware.

Sob os requisitos de ergonomia, conforme a NBR ISO 9241-11 (1998), a usabilidade é definida como "o grau em que um produto é usado por usuários específicos para atingir objetivos específicos com eficácia, eficiência e satisfação dentro do contexto de uso específico”.

Nielsen (2003) conceitua usabilidade, na visão da engenharia de usabilidade, como sendo um conjunto de cinco fatores que qualificam a interação do usuário com o sistema (tanto software como hardware): 
- Facilidade de aprendizado: refere-se ao tempo e esforço necessários para que o usuário aprenda a utilizar o sistema com determinado nível de competência e desempenho.

- Facilidade de recordação: diz respeito ao esforço cognitivo do usuário, necessário para lembrar, como interagir com a interface do sistema, conforme aprendido anteriormente.

- Eficiência: está relacionada ao tempo necessário para a conclusão de uma atividade com o apoio computacional.

- Segurança no uso: grau de proteção de um sistema contra condições desfavoráveis ou até mesmo perigosas para o usuário.

- Satisfação do usuário: uma avaliação subjetiva que expressa o efeito do uso do sistema sobre as emoções e sentimentos do usuário.

Para a norma NBR ISO 13407 (1999), existem quatro atividades que devem ser utilizadas para incorporar requisitos de usabilidade, no processo de desenvolvimento computacional centrado no usuário (Figura 1); são elas: analisar, especificar, produzir e avaliar.

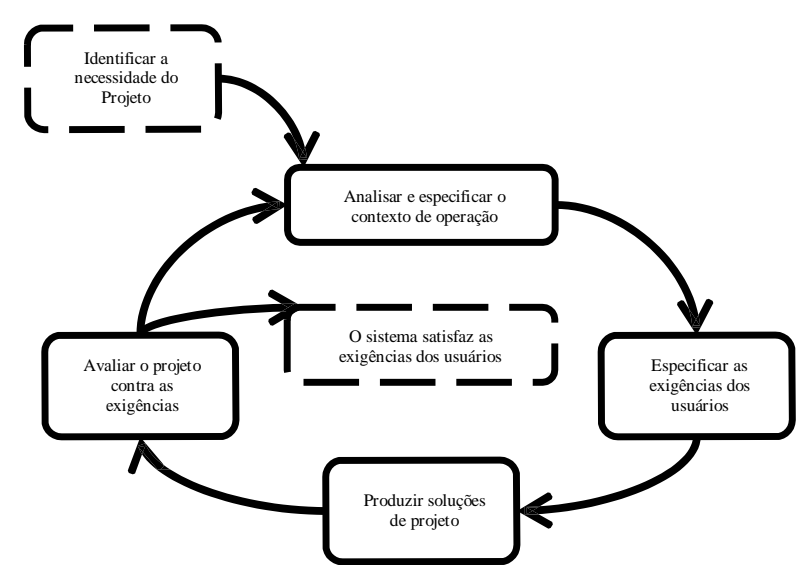

Figura 1 - Ciclo do Projeto centrado no Usuário

A partir dos requisitos de identificação das necessidades dos usuários, é analisado e especificado o contexto da operação, juntamente com as exigências dos mesmos, a fim de produzir soluções para o projeto; nessa fase são consideradas as etapas de implementação, tanto de software como de hardware. Fechando o ciclo (Figura 1), o projeto é avaliado verificando se as exigências e necessidades foram alcançadas; se sim, consideramos, então, que o projeto foi finalizado com sucesso. Se não, o ciclo é novamente executado até que o produto final cumpra suas exigências específicas, entre elas a acessibilidade, quando falamos em pessoas com deficiência.

O Decreto $\mathrm{N}^{\circ} 5.296$ apresenta o conceito de acessibilidade como sendo a, condição para utilização, com segurança e autonomia, total ou assistida, dos espaços, mobiliários e equipamentos urbanos, das edificações, dos serviços de transporte e dos dispositivos, sistemas e meios de comunicação e informação, por pessoa portadora de deficiência ou com mobilidade reduzida (BRASIL, 2004).

O critério de acessibilidade computacional está relacionado com a capacidade do usuário de acessar o sistema, para interagir com ele, sem que a interface imponha obstáculos. Barbosa e Silva (2010, p. 33) explicam que uma interface acessível "não pode impor barreiras para a integração e para o acesso à informação, nem no hardware e nem no software do sistema interativo".

Quando falamos em deficientes visuais, a acessibilidade perpassa pelo projeto arquitetônico e urbano, pelos transportes coletivos, pelo acesso à informação e à comunicação e pelas ajudas técnicas. Como o foco do estudo é a questão educacional e 
computacional, daremos ênfase à informação e à comunicação, integrada com o design instrucional.

As barreiras nas comunicações e nas informações, relatadas pelo Decreto 5.296 referem-se a,

qualquer entrave ou obstáculo que dificulte ou impossibilite a expressão ou o
recebimento de mensagens por intermédio dos dispositivos, meios ou
sistemas de comunicação, sejam ou não de massa, bem como aqueles que
dificultem ou impossibilitem o acesso à informação (BRASIL, 2004).

Uma das barreiras de interface encontradas pelas pessoas com deficiência visual é justamente o fato de que a maioria dos sistemas apresenta uma interface com recursos gráficos; para o cego, contudo, ela deve ser textual, de modo que os leitores de tela possam "falar" todos os seus componentes.

Vencer essas barreiras de acesso é uma das busca dos designers, pois construir produtos contemplando os requisitos do design instrucional, da acessibilidade e da usabilidade ainda é um grande desafio.

Um termo utilizado pelos designers para especificar essa busca é a comunicabilidade. Este se refere à remoção de qualquer barreira da interface que impeça o usuário de interagir (acessibilidade), tornando-se de fácil uso (usabilidade) e que possibilite uma comunicação das concepções e intenções do sistema interativo; ou seja, no caso dos deficientes visuais, o produto precisa "falar” com o usuário.

\section{CONSTRUÇÃO DA CONTÁTIL}

Partindo da pergunta de pesquisa: "Quais as potencialidades e limitações de uma Tecnologia Assistiva, implementada para o ensino de conceitos básicos de Matemática, considerando a deficiência visual?”, na percepção dos professores que atuam com alunos cegos e/ou baixa visão, iniciamos os trabalhos delineando os objetivos.

Definimos como objetivo geral: implementar a Tecnologia Assistiva Contátil, baseada no Material Dourado, para o ensino de conceitos básicos de Matemática a alunos cegos e/ou baixa visão.

A primeira etapa foi projetar como seria o equipamento e quais tecnologias seriam empregadas, tanto computacionais como mecânicas. O primeiro esboço foi feito com a ajuda de um Engenheiro Mecânico que, a partir da descrição da funcionalidade do protótipo, desenhou suas peças principais e dimensões, conforme é apresentado na Figura 2.

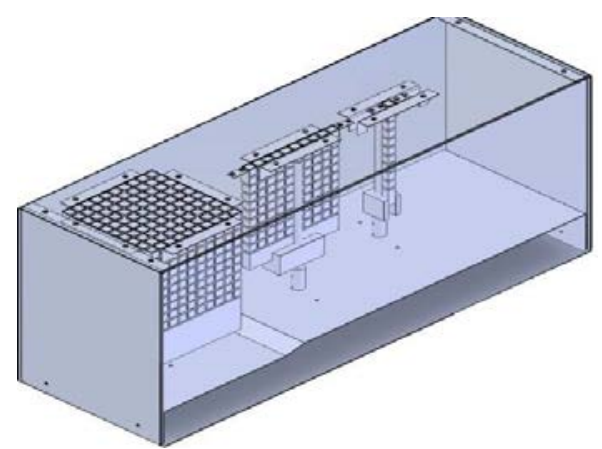

Figura 2 - Esboço da Contátil

Para especificar as peças referentes ao Material Dourado (unidades, dezenas e centenas), foi necessário um desenho explicativo, a fim de auxiliar na confecção das mesmas. Diferente do material dourado tradicional, o protótipo, por ser projetado para alunos com deficiência visual, possui uma característica peculiar: as peças são agrupadas, ou seja, elas estão dispostas umas sobre as outras (Figura 3), formando 3 blocos - o das unidades, o das dezenas e o das centenas. Esse agrupamento se deu pelo 
fato que as pessoas com deficiência visual usam o tato para visualizar as quantidades, sendo necessária uma organização espacial.
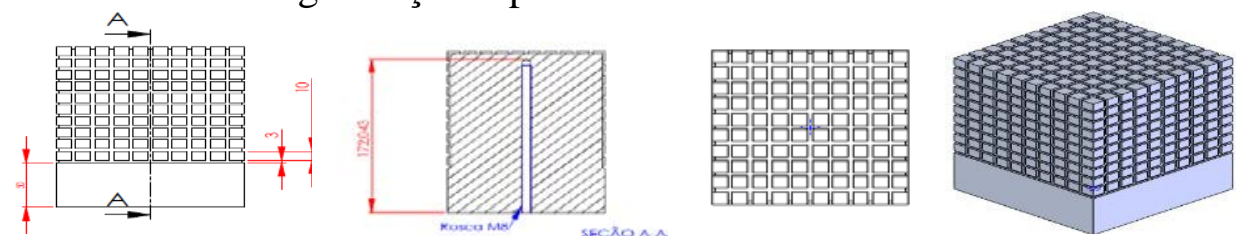

Figura 3 - Croqui do Bloco referente às Centenas

O Material Dourado foi idealizado e utilizado por Maria Montessori, uma médica e educadora italiana, para trabalhar com crianças que apresentavam distúrbios de aprendizagem na aritmética (SILVA; ARAUJO, 2011).

O material é constituído por cubinhos que representam as unidades (Figura 4a), barras representando as dezenas (Figura 4b), placas compondo as centenas (Figura 4c) e o cubo que forma o milhar (Figura 4d).
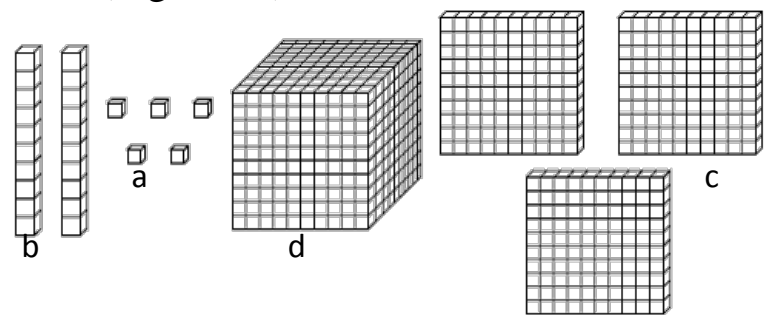

Figura 4 - Material Dourado

Fonte: http://professorwellingtonmatematicagestar2.blogspot.com.br/2010_04_01_archive.html

Obedecendo aos critérios do design universal, quanto ao desenvolvimento centrado no usuário, as peças, unidades (Figura 5c), dezenas (Figura 5b) e centenas (Figura 5a), foram agrupadas, compondo assim uma adaptação tátil do material dourado, para os alunos cegos, como mencionado anteriormente.

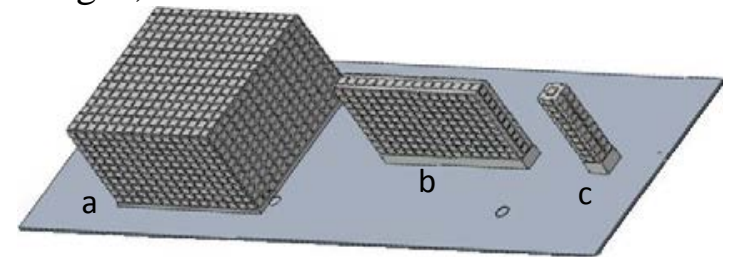

Figura 5 - Croqui das Peças da Contátil

O protótipo possui dimensão externa de $20 \mathrm{~cm} \times 30 \mathrm{~cm} \times 60 \mathrm{~cm}$, correspondendo respectivamente a largura, altura e comprimento.

O material escolhido para a confecção das peças foi o polietileno, por ser um material resistente e possível de ser moldado. Além de sua cor neutra (branca). A Figura 6 mostra a caixa externa (Figura 6a), as peças da centena e dezena apenas cortadas (Figura 6b) e um dos pinos (Figura 6c) que são responsáveis pela movimentação (subir e descer) das peças.

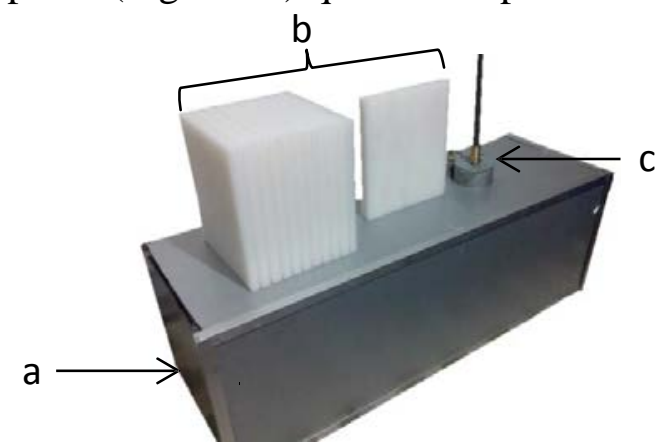

Figura 6 - Caixa, Peças e Pino (Contátil)

Para a movimentação dos blocos, foram utilizados motores de passos (Figura 7). Esses motores são acionados através de pulsos elétricos que possibilitam a 
movimentação em um determinado ângulo; tal característica provê precisão nos movimentos. Para a transferência de movimento, acoplou-se ao eixo de cada motor uma barra roscada, que ao ser encaixada internamente nas peças possibilita a movimentação para cima ou para baixo. O sistema de controle dos motores foi implementado em linguagem C e é executado através de um microcontrolador ARM Cortex M3 LPC1768 da NXP.

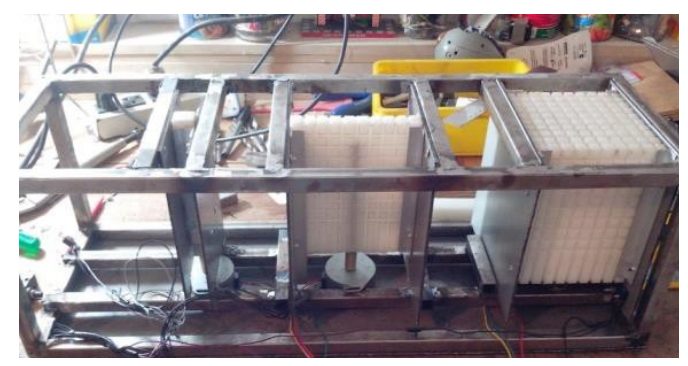

Figura 7 - Contátil internamente

Após a construção física e a programação do Sistema Embarcado para controle dos equipamentos, obtivemos a finalização do protótipo, que recebeu o nome de Contátil (Figura 8). A partir desse momento, iniciou-se a etapa das entrevistas com os professores, sujeitos deste estudo, cuja finalidade foi validar/verificar o potencial da Contátil no ensino de alunos cegos e/ou com baixa visão.

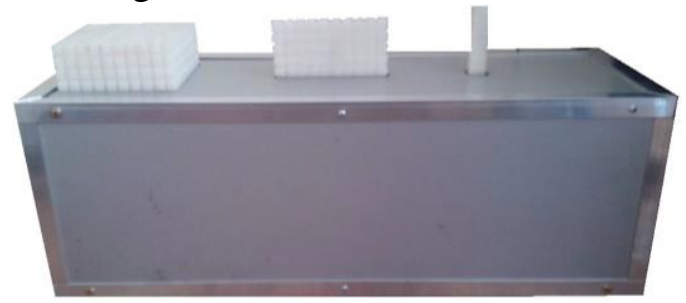

Figura 8 - Contátil

A Contátil apresenta três opções de uso, sendo acionadas por seus correspondentes números: 1 - Aprendizado dos Números (0 a 999); 2 - Calculadora Tátil (operações de adição, subtração, multiplicação e divisão, com duas parcelas e resultado até 999, operações somente com números positivos) e 3 - Atividades.

No Aprendizado dos Números (Opção 1), o aluno ou o professor devem inserir valores numéricos de 0 a 999 através do teclado acoplado na Contátil. Ao digitar um número, automaticamente será falado, com o auxílio de caixas de som, seu valor e apresentada a quantidade correspondente com o auxilio das peças (unidades, dezenas e centenas), fazendo com que o usuário possa tatear o valor da mesma forma que no Material Dourado.

Por exemplo, se for digitado o valor 101, subirá um cubo da unidade, nenhuma barra da dezena e uma placa da centena (Figura 9). Dessa forma é possível trabalhar, além da quantidade, o valor posicional de cada número em questão.

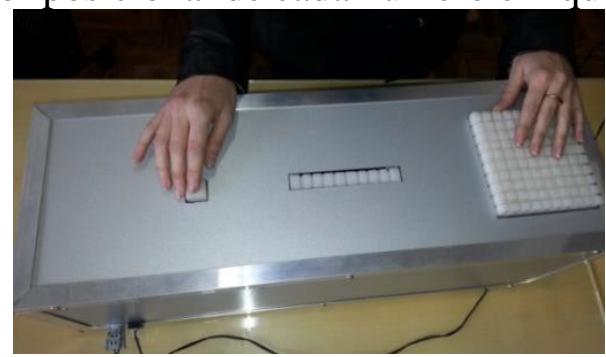

Figura 9 - Representação do valor 101

A opção 2 - Calculadora Tátil - efetua as quatro operações básicas: adição, subtração, multiplicação e divisão, desde que apenas com duas parcelas e cujo resultado máximo seja 999. Assim como no aprendizado dos números, são falados os valores, a 
operação matemática e o respectivo resultado, juntamente com a quantidade, para que possa ser percebido através do tato.

A dinâmica da calculadora é composta por três fases: inserção da primeira parcela; inserção do operador matemático referente à operação que se deseja efetuar (+ para adição; - para subtração; * para multiplicação; / para divisão); e inserção da segunda parcela. Ao finalizar a segunda parcela com o "Enter" do teclado, o protótipo inicia o processo de exibição tátil e auditiva do resultado. No primeiro momento é falada a operação matemática que foi inserida e, logo após, as peças são movimentadas de forma a apresentar o valor final, sendo possível a sua verificação através do tato.

As atividades (Opção 3) correspondem a uma sequência de perguntas que o usuário deverá ouvir e inserir o valor correspondente, como, por exemplo, "quantas unidades são necessárias para compor uma dezena?”, ou “duas dezenas e cinco unidades foram que valor?”. Após a inserção do valor, é apresentado o resultado, tanto falado como tátil.

Finalizada a etapa da construção do protótipo, voltamos ao design centrado no usuário (Figura 10), no qual adaptamos e apresentamos o ciclo de desenvolvimento. Em função das necessidades dos usuários serem específicas, devendo contemplar a usabilidade e acessibilidade, aliadas ao desenho universal, foram elaborados testes nesses quesitos durante todo o processo.

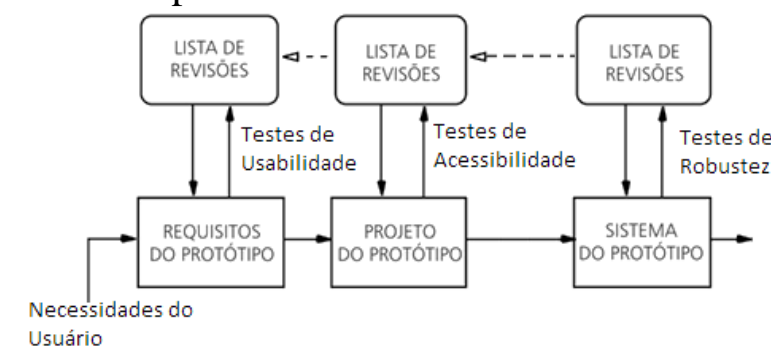

Figura 10 - Ciclo de Desenvolvimento Centrado no Usuário do Protótipo

Fonte: Adaptado de CYBIS; BETIOL; FAUST (2007)

Após a definição do tema e a implementação da Contátil, optou-se por realizar uma pesquisa do tipo qualitativa, com o propósito de validar/avaliar, tendo como sujeitos professores licenciados em Matemática e professores que atendem em Sala de Recursos, os quais atuam ou atuaram com alunos cegos e/ou baixa visão, com o intuito principal de buscar opiniões e sugestões para essa Tecnologia Assistiva.

Foram entrevistados 19 professores das redes municipal, estadual e particular de ensino da região metropolitana de Porto Alegre. O critério de escolha foi a experiência com alunos cegos e/ou baixa visão no ensino de Matemática. A opção de validar, nesse momento, deu-se em função de considerarmos fundamental verificar com professores as potencialidades e/ou limitações da tecnologia para que pudessem ser desenvolvidas melhorias.

\section{VALIDAÇÃO DA CONTÁTIL}

O desenvolvimento da Contátil teve como princípio as recomendações de usabilidade e acessibilidade, respeitando o ciclo de desenvolvimento centrado no usuário. Durante todo o processo foram efetuados testes para que as especificidades dos deficientes visuais fossem atendidas. A fala de um professor entrevistado confirma "é diferente de só escutar no computador, aqui eles têm o manuseio, têm a percepção com as mãos”.

Durante as entrevistas percebemos que os professores que possuem o curso de Magistério são mais atentos na ludicidade e manuseio pelo tato do Material Dourado, já 
os que cursaram o Ensino Médio ou algum profissionalizante, se preocupam mais com as questões algorítmicas.

Um dos professores relatou no início da sua entrevista a importância do uso do Material Dourado na alfabetização matemática:

$\mathrm{Na}$ verdade o deficiente visual, o cego, aprende muito pelo tato, é basicamente o tato, além da audição e de outros sentidos. Uma das coisas fundamentais para a criança com deficiência visual é o material dourado, é onde ela consegue construir a unidade, dezena, centena. Porque tem de tamanhos diferentes, é de tamanhos diferentes, dá para contar as unidades na dezena, dá para contar que são 10 unidades na dezena 'grudadinhas'.

Como a Contátil possuí a característica de ser concreta, o usuário pode reconhecer através do tato os valores apresentados e, principalmente ter certeza de que o valor está correto, possibilitando assim à criança sentir o valor associado à sua quantidade.

Dentre as potencialidades os professores destacaram que a Contátil proporciona a visualização através do tato do material dourado corretamente; é segura, não apresenta nenhum risco ao aluno no tatear, tudo foi lixado, não tem como a criança se machucar ao tocar no equipamento; as peças estão bem vincadas, o que facilita o tato; é simples, de fácil manuseio; trabalha com os princípios do material dourado, que é o primeiro a ser abordado com os alunos pequenos; trabalha com o sistema numérico posicional, que é a base.

Quanto às limitações, os professores indicaram que o barulho atual deveria ser amenizado e sugeriram inserir sons diferenciados para que os alunos possam identificar a unidade, dezena e centena. Houve também a sugestão de se acrescentarem fones de ouvido e diminuir o espaço entre as unidades, dezenas e centenas. Essas limitações serviram de base para as modificações realizadas na nova versão da TA.

\section{CONSIDERAÇÕES FINAIS}

A tecnologia está presente no nosso dia a dia e a educação pode usufruir de seus benefícios. A construção de uma TA voltada aos deficientes visuais proporciona um ensino mais dinâmico, confirmado por um entrevistado,

O uso do material dourado, explorar essa construção do sistema da numeração decimal é extremamente importante e tu ter um recurso de tecnologia, algo que se movimenta, eu acho que isso torna mais atrativo ainda se tratando, para todo mundo, mas a criança também, acho que isso, assim eu considero importante, válido!

$\mathrm{Na}$ maioria das atividades apresentadas pelos professores, percebe-se a preocupação com a visualização/tato da quantidade correta e com o valor posicional. Para muitos essas são questões essenciais para que o aluno cego possa abstrair e consequentemente efetuar operações matemáticas de forma correta, utilizando as unidades, dezenas e centenas em sua posição original.

\section{REFERÊNCIAS BIBLIOGRÁFICAS}

BARBOSA, S. D. J.; SILVA, B. S. da. Interação Humano-Computador. Rio de Janeiro: Elsevier, 2010.

BERSCH, R. Introdução à Tecnologia Assistiva. Assistiva - Tecnologia e Educação. Porto Alegre, 2013. Disponível em: http://www.assistiva.com.br/Introducao_Tecnologia_ Assistiva.pdf. Acesso em 01 de mar. de 2014.

BERSCH, R. Introdução à Tecnologia Assistiva. CEDI - Centro Especializado em

Desenvolvimento Infantil, Porto Alegre, 2008. Disponível em: 
http://proeja.com/portal/images/semana-quimica/2011-10-19/tec-assistiva.pdf. Acesso em 20 jun. de 2014.

BRASIL. Decreto n ${ }^{0} 5.296$ de 02 de dezembro de 2004. Estabelece normas gerais e critérios básicos para a promoção da acessibilidade das pessoas portadoras de deficiência ou com mobilidade reduzida. Brasília, 2004. Disponível em:

http://www.planalto.gov.br/ccivil_03/_ato2004-2006/2004/ decreto/d5296.htm. Acesso em 31 de maio de 2014

CARVALHO, J. O. F. O papel da interação humano-computador na inclusão digital. Periódicos PUC-Campinas. v. 15, n. 3, 2003. Disponível em: http://periodicos.puccampinas.edu.br /seer/index.php/transinfo/article/view/1461/0. Acesso em 20 de set. de 2014.

CYBIS, W.; BETIOL, A. H. e FAUST, R. Ergonomia e Usabilidade: Conhecimentos, Métodos e Aplicações. São Paulo: Novatec Editora, 2007.

FILATRO, A. Design instrucional na prática. São Paulo: Editora Pearson Education do Brasil, 2008.

GALVÃO FILHO, T. A. Tecnologia Assistiva para uma Escola Inclusiva: Apropriação, Demandas e Perspectivas. Tese de Doutorado do Programa de Pós-Graduação em Educação. Faculdade de Educação. Universidade Federal da Bahia. Salvador, 2009. Disponível em:

https://docs.google.com/file/d/0BydaUKFWgob9Yjg4ZTk0MmUtYWZhYS00MGQ1LTg w NGQtMjc5MWY5MDYzZmMy/edit?pli=1\&hl=pt_BR\#. Acesso em 31 de maio de 2014. INR. Instituto Nacional para a Reabilitação. Desenho Universal. Disponível em: http://www.inr.pt/content/1/5/desenho-universal. Acesso em 20 de set.de 2014.

NBR ISO 13407. Design de Processos Centrados no Usuário. Brasília, 1999. Disponível em: http://www.iso.org/iso/catalogue_detail.htm?csnumber=21197. Acesso em 05 de nov. de 2014.

NBR ISO/IEC 9126-1. Engenharia de Software - Qualidade de Produto. Rio de Janeiro, 1991. Disponível em: http://luizcamargo.com.br/arquivos/NBR\%20ISO_IEC\%2091261.pdf. Acesso em 03 de nov. de 2014.

NIELSEN, J. Projetando Websites. Rio de Janeiro: Editora Campus, 2003.

NRB ISO 9241-11. Requisitos Ergonômicos para Trabalhos de Escritórios com

Computadores. Parte 11 - Orientações sobre Usabilidade. Rio de Janeiro, 1998.

Disponível em: http://www.inf.ufsc.br/ cybis/pg2003/iso9241-11F2.pdf. Acesso em 04 de nov. de 2014. SANTAROSA, L. M. C. Cooperação na Web entre PNEE: construindo conhecimento no Núcleo de Informática na Educação Especial da Ufrgs. In: Congresso Ibero-americano de Informática na Educação Especial. III CIEE - SEESP/MEC. Fortaleza: ago. 2002, p. 64-79. Disponível em:

http://www.ufrgs.br/niee/producoes.php?cat=0\&lc=1\&tp=2. Acesso em 20 jul. de 2014. SILVA, S. A. da; ARAUJO, J. A. A. de. Maria Montessori e a Criação do Material Dourado como Instrumento Metodológico para o Ensino de Matemática nos anos iniciais da escolarização. Universidade Estadual de Mato Grosso do Sul (UEMS). Mato Grosso do Sul, 2011. Disponível em:

http://www.uems.br/eventos/semana/arquivos/31_2011-09-05_14-28-02.pdf. Acesso em 20 de jul. de 2014. 